\title{
A Replication of "Using self-esteem to disaggregate psychopathy, narcissism, and aggression (2013)”
}

\author{
Guillaume Durand ${ }^{\mathrm{a}, \boldsymbol{}}$ \\ ${ }^{a}$ Department of Clinical Psychological Science, Maastricht University, Maastricht, Netherlands
}

\begin{tabular}{|c|c|}
\hline $\begin{array}{l}\text { Abstract } \square \text { The present study is a replication of Falkenbach, Howe, and Falki (2013). Using self- } \\
\text { esteem to disaggregate psychopathy, narcissism, and aggression. Personality and Individual Differ- } \\
\text { ences, } 54(7), 815-820 \text {. }\end{array}$ & $\begin{array}{l}\text { Acting Editor } \text { 口 De- } \\
\text { nis Cousineau (Uni- } \\
\text { versité d'Ottawa) }\end{array}$ \\
\hline Keywords - replication study, psychopathy, narcissism, self-esteem, aggression. & \multirow{4}{*}{$\begin{array}{l}\text { Reviewers } \\
\text { One anonymous re- } \\
\text { viewer. }\end{array}$} \\
\hline$\triangle$ gdura061@uottawa.ca & \\
\hline (iD) $G D: 0000-0002-5418-4429$ & \\
\hline doi) $10.20982 /$ tqmp.12.2.r001 & \\
\hline
\end{tabular}

\section{Introduction}

Psychopathy is a personality-based condition that describes individuals possessing characteristics such as superficial charm, dishonesty, narcissism, lack of remorse or empathy, and impulsive behaviors (Cleckley, 1941). Psychopathy can be subdivided into two factors: Fearless Dominance (PPI-I), which reflects adaptive behaviors, and Self-Centered Impulsivity (PPI-II), which reflects maladaptive behaviors (Fowles \& Dindo, 2009). Due to the negative aspects of psychopathy, several misconceptions have arisen, such as the positive correlation between psychopathy and violence (Berg et al., 2013). While psychopathy is a possible risk factor for aggressive behaviors, prior investigations have concluded that a significant percentage of psychopathic individuals are well-adapted to society and do not engage in any major criminal activities (Hall \& Benning, 2006; Lynam \& Miller, 2012; Widom, 1977).

In addition to aggressive behaviors, narcissism and self-esteem have also been investigated in connection with psychopathy. Narcissism is a pervasive personality pattern characterized by grandiosity, self-attention, and selfimportance (DSM-IV-TR; American Psychiatric Association (2000)). Similar to psychopathy, narcissism is divided into two factors: healthy narcissism and pathological narcissism. The former includes individuals who are arrogant, self-dominant, and adapted to their environment, while the latter includes individuals who possess a superficial sense of greatness, but who also are vulnerable, anxious, and defensive (Pincus \& Lukowitsky, 2010; Wink,
1991). Prior research suggests that psychopathy and narcissism are closely interrelated (Skeem, Poythress, Edens, Lilienfeld, \& Cale, 2003). Unlike psychopathy and narcissism, self-esteem is not subdivided, although prior investigations have shown evidence that high self-esteem is related to Fearless Dominance and healthy narcissism, while low self-esteem is related to Self-Centered Impulsivity and pathological narcissism (Cale \& Lilienfeld, 2006; Maxwell, Donnellan, Hopwood, \& Ackerman, 2011; Rozenblatt, 2002).

In order to further investigate the relationship between psychopathy, aggression, narcissism, and selfesteem, Falkenbach, Howe, and Falki (2013) recruited 118 undergraduates for the purpose of assessing how selfesteem relates to psychopathy and narcissism, and to determine the predictive value of the two latter constructs on aggression. Their results suggested a positive correlation between high levels of PPI-I and healthy narcissism, alongside high self-esteem and low aggression. At the opposite end, individuals with high levels of PPI-II and pathological narcissism displayed lower self-esteem and higher aggression. The purpose of the present study is to replicate the previous findings to further confirm the relationship between psychopathy, narcissism, aggression, and self-esteem in a community sample. 
Table 1 - Means, standard deviations (SD), and alpha coefficients.

\begin{tabular}{|c|c|c|c|}
\hline Scale & Mean & SD & alpha \\
\hline \multicolumn{4}{|c|}{ Psychopathic Personality Inventory } \\
\hline PPISF Total & 130.66 & 14.39 & .76 \\
\hline PPISF-I & 51.32 & 8.66 & .75 \\
\hline PPISF-II & 64.76 & 9.99 & 78 \\
\hline \multicolumn{4}{|c|}{ Narcissistic Personality Inventory } \\
\hline NPI Total & 11.62 & 6.22 & .82 \\
\hline NPI Healthy & 8.33 & 4.79 & 79 \\
\hline NPI Pathological & 3.29 & 2.02 & .52 \\
\hline \multicolumn{4}{|c|}{ State Self-Esteem Scale } \\
\hline SSES Total & 65.16 & 14.81 & 91 \\
\hline SSES Performance & 25.59 & 5.84 & .85 \\
\hline SSES Social & 22.26 & 6.17 & 83 \\
\hline SSES Appearance & 17.29 & 5.47 & .86 \\
\hline \multicolumn{4}{|c|}{ Aggression Questionnaire } \\
\hline $\mathrm{AQ}$ & 65.89 & 12.69 & 87 \\
\hline
\end{tabular}

Note. Note. SSES = State Self-Esteem Scale; NPI = Narcissistic Personality Inventory; PPISF = Psychopathic Personality Inventory; $\mathrm{AQ}=$ Aggression Questionnaire

\section{Method}

\section{Participants}

A total of 127 participants from the community were recruited for the experiment. Participants were $29 \%$ female ( $n=37$ ) and $71 \%$ male $(n=90)$. The age range was between 18 and 51 years old $(M=25, S D=6.77)$. Participants were primarily Caucasian (79\%), Asian (13\%), or other (8\%). Participants were mostly located in Europe (60\%), North America (18\%), Asia (13\%), or other (9\%). Participants were mostly located in Europe (60\%), North America (18\%), Asia (13\%) and other (9\%). The primary language spoken by participants was English (38\%), other (31\%), German (10\%), French (9\%), Dutch (8\%), and Spanish (4\%). All participants provided informed consent prior to filling out the questionnaires.

\section{Materials and Procedure}

The procedure for this experiment was the same as the one used by Falkenbach et al. (2013), except for the following two differences. First, the Psychopathic Personality Inventory-Short Form (PPI-SF; Lilienfeld and Widows (2005)) was used instead of the standard version of the Psychopathic Personality Inventory (PPI; Lilienfeld and Andrews (1996)). The PPI-SF was developed by selecting the seven items with the highest loadings in factor analyses from each of the eight subscales, resulting in a 56-item version instead of the original 187-item version (Lilienfeld, Latzman, Watts, Smith, \& Dutton, 2014). The PPI-SF correlates highly with the standard version $(r=.90)$ and pos- sesses good reliability ( $\alpha=.81$ ) (Lilienfeld \& Hess, 2001; Mullins-Nelson, Salekin, \& Leistico, 2006). Second, instead of the initial Rosenberg Self-Esteem Scale (RSES; Rosenberg (1965)), an alternative measure was used. While the RSES is one of the most validated tools for assessing selfesteem, cross-cultural differences have been observed to affect measurements, including a preference among collectivist cultures for giving neutral responses (Schmitt \& Allik, 2005). And since the current study is a worldwide community replication, an alternative measure for assessing self-esteem was needed. We used the State Self-Esteem Scale (SSES; Heatherton and Polivy (1991)). The SSES correlates well with the RSES $(r=.72)$ and possesses good test-retest properties ( $r=.72$ ) (Heatherton \& Polivy, 1991). The measure is divided into three subscales: Performance (SSES-P), Social (SSES-S), and Appearance (SSES-A). Using a measure that assesses self-esteem at a given point instead of as a general condition can further illustrate the generalizability of its role in psychopathy, narcissism, and aggression. The measures of narcissism and aggression previously used by Falkenbach et al. (2013), the Narcissistic Personality Inventory (NPI; Raskin and Terry (1988)) and the Aggression Questionnaire (AQ; Buss and Perry (1992)), remained unchanged in the present replication.

\section{Results}

Table 2 shows the correlations between the questionnaires. The subscales of the PPI were significantly correlated with the PPI total score, but not with each other. The subscales of the NPI were also significantly correlated with the NPI total score, but were also strongly correlated with 
Table 2 a Correlations Between Psychopathy, Narcissism, Self-esteem, and Aggression

\begin{tabular}{|c|c|c|c|c|c|c|c|c|c|c|}
\hline Scale & PPI-T & PPI-I & PPI-II & NPI-T & NPI-H & NPI-P & SSES-T & SSES-P & SSES-S & $\mathrm{AQ}$ \\
\hline PPI-T & & & & & & & & & & $.41^{* *}$ \\
\hline PPI-I & $.69^{* *}$ & & & & & & & & & -.02 \\
\hline PPI-II & $.74^{* *}$ & .11 & & & & & & & & $.62^{* *}$ \\
\hline NPI-T & $.39^{* *}$ & $.47^{* *}$ & .08 & & & & & & & .10 \\
\hline NPI-H & $.31^{* *}$ & $.46^{* *}$ & .00 & $.97 * *$ & & & & & & .05 \\
\hline NPI-P & $.44^{* *}$ & $.37^{* *}$ & $.24^{* *}$ & $.79 * *$ & $.60^{* *}$ & & & & & $.20^{*}$ \\
\hline SSES-T & $.18^{*}$ & $.50^{* *}$ & $-.28^{* *}$ & $.51^{* *}$ & $.54^{* *}$ & $.28^{* *}$ & & & & $-.28^{* *}$ \\
\hline SSES-P & .16 & $.43^{* *}$ & $-.21^{*}$ & $.46^{* *}$ & $.49^{* *}$ & $.26^{* *}$ & $.86^{* *}$ & & & $-.25^{* *}$ \\
\hline SSES-S & $.23^{* *}$ & $.47^{* *}$ & $-.22^{*}$ & $.39 * *$ & $.41^{* *}$ & $.22^{*}$ & $.88^{* *}$ & $.65^{* *}$ & & $-.23^{*}$ \\
\hline SSES-A & .06 & $.37^{* *}$ & $-.28^{* *}$ & $.44^{* *}$ & $.47^{* *}$ & $.23^{*}$ & $.80^{* *}$ & $.51^{* *}$ & $.55^{* *}$ & $-.24^{* *}$ \\
\hline
\end{tabular}

Note. ${ }^{*} \mathrm{p}<.05,{ }^{* *} \mathrm{p}<.01$.

Table 3 a Regression Model Predicting AQ

\begin{tabular}{lcccc}
\hline Scale & Standard error & $\beta$ & $\mathrm{t}$ & Significance \\
\hline PPISF-II & .10 & .55 & 6.83 & .00 \\
NPI-P & .50 & .11 & 1.36 & .18 \\
SSES-T & .07 & -.15 & -.15 & .07 \\
\hline
\end{tabular}

each other $(r=.60)$. The same pattern was observed with the subscales of the SSES, which were significantly correlated with both the SSES total score and each other. A strong positive correlation was found between psychopathy and narcissism $(r=.39)$, as well as between psychopathy and aggression $(r=.41)$. The correlation between psychopathy and self-esteem was weaker, but remained significant $(r=.18)$.

When analyzing the results by psychopathy subscales, the results showed that PPI-I was strongly positively correlated with the NPI and all of its subscales, as well as with the SSES and all of its subscales. No correlation was found between PPI-I and AQ. At the opposite end, PPIII was not significantly correlated with either the NPI or NPI-H, but had a weak but still significant positive correlation with the NPI-P $(r=.24)$. The PPI-II was also significantly negatively correlated with the SSES and all of its subscales, but showed a strong positive correlation with the AQ $(r=.62)$. The NPI displayed a strong positive correlation with the SSES $(r=.51)$ and all of its subscales, but no correlation with the AQ. When analyzed by subscales, the NPI-H and NPI-P were both positively correlated with self-esteem. However, only the NPI-P was positively correlated with the AQ $(r=.20)$. Finally, the SSES and all of its subscales showed significant negative correlation with the AQ.

As shown in Table 3, the inclusion of PPISF-II, NPI$\mathrm{P}$, and SSES-T resulted in a significant prediction model $(F(3,115)=26.018, p<.001)$. This model accounted for $63.6 \%$ of the variance in the AQ $\left(R^{2}=.40\right.$, adjusted
$\left.R^{2}=.39\right)$. The PPI-II $(\beta=.55, t=6.83, p<.001)$ was the only significant independent predictor of AQ.

\section{Discussion}

Overall, the current results replicated the previous findings of Falkenbach et al. (2013). Despite some differences in mean scores of the NPI and its subscales, the current results for PPI-I and NPI-H are similar to previous results, supporting a correlation between high PPI-I, high NPI-H, high self-esteem, and low aggression. While largely similar, a few differences emerged on the other scales. The PPI-II of the current study was negatively associated with self-esteem and positively associated with aggression, as in previous findings; however, in the current study, PPI-II was only correlated positively with the NPI-P subscale, while it has previously been correlated with every scale of the NPI. Another difference lies in the correlation between NPI-P and self-esteem. In the original study, the authors reported a partial negative correlation between NPI-P and RSES. In the current study, NPI-P and self-esteem on all scales were significantly positively correlated. Finally, the PPI-II of this study was once again the main component predicting aggression. While almost significant, the SSES was unable to replace the modified version of the RSES, which assesses the stability of self-esteem, in the regression model of the AQ. Despite these few differences, the current study was able to confirm the previous findings regarding the links between psychopathy, narcissism, self-esteem, and aggression. 


\section{References}

American Psychiatric Association. (2000). Diagnostic and statistical manual-text revision.

Berg, J. M., Smith, S. F., Watts, A. L., Ammirati, R., Green, S. E., \& Lilienfeld, S. O. (2013). Misconceptions regarding psychopathic personality: implications for clinical practice and research. Neuropsychiatry, 3, 63-74. Retrieved from http://doi.org/10.2217/npy.12.69

Buss, A. H. \& Perry, M. (1992). The aggression questionnaire. Journal of Personality and Social Psychology, 62(3), 98-109.

Cale, E. M. \& Lilienfeld, S. O. (2006). Psychopathy factors and risk for aggressive behavior: a test of the "threatened egotism" hypothesis. Law and Human Behavior, 30(1), 51-74. Retrieved from http://doi.org/10.1007/ s10979-006-9004-5

Cleckley, H. (1941). The mask of sanity; an attempt to reinterpret the so-called psychopathic personality. Jama, 117(6), 493. Retrieved from http://doi.org/10.1001/ jama.1941.02820320085028

Falkenbach, D. M., Howe, J. R., \& Falki, M. (2013). Using self-esteem to disaggregate psychopathy, narcissism, and aggression. Personality and Individual Differences, 54(7), 815-820. Retrieved from http:// doi. org/10.1016/j.paid.2012.12.017

Fowles, D. C. \& Dindo, L. (2009). Temperament and psychopathy: a dual-pathway model. Current Directions in Psychological Science, 18(3), 179-183. Retrieved from http://doi.org/10.1111/j.1467-8721.2009.01632.x

Hall, J. R. \& Benning, S. D. (2006). The "successful” psychopath: adaptive and subclinical manifestations of psychopathy in the general population. In Handbook of psychopathy (pp. 459-478.

Heatherton, T. F. \& Polivy, J. (1991). Development and validation of a scale for measuring state self-esteem. Journal of Personality and Social Psychology, 60(6), 895910. Retrieved from http://doi . org/10 .1037/0022 3514.60.6.895

Lilienfeld, S. O. \& Andrews, B. (1996). Development and preliminary validation of a self-report measure of psychopathic personality traits in noncriminal populations. Journal of Personality Assessment, 66(3), 488524. Retrieved from http : / / doi . org / 10 . 1207 / s15327752jpa6603_3

Lilienfeld, S. O. \& Hess, T. T. H. T. (2001). Psychopathic personality traits and somatization: sex differences and the mediating role of negative emotionality. Journal of Psychopathology and Behavioral, 23(1), 11-24. Retrieved from http://doi.org/10.1023/A:1011035306061

Lilienfeld, S. O., Latzman, R. D., Watts, A. L., Smith, S. F., \& Dutton, K. (2014). Correlates of psychopathic personality traits in everyday life: results from a large com- munity survey. Frontiers in Psychology, 5, 1-11. Retrieved from http://doi.org/10.3389/fpsyg.2014.00740

Lilienfeld, S. O. \& Widows, M. (2005). Psychopathic personality inventory-revised: professional manual. Lutz, FL: Psychological Assessment Resources.

Lynam, D. R. \& Miller, J. D. (2012). Fearless dominance and psychopathy: a response to lilienfeld et al. Personality Disorders: Theory, Research, and Treatment, 3(3), 341353. Retrieved from http://doi.org/10.1037/a0028296

Maxwell, K., Donnellan, M. B., Hopwood, C. J., \& Ackerman, R. A. (2011). The two faces of narcissus? An empirical comparison of the Narcissistic Personality Inventory and the Pathological Narcissism Inventory. Personality and Individual Differences, 50(5), 577-582. Retrieved from http://doi.org/10.1016/j.paid.2010.11.031

Mullins-Nelson, J. L., Salekin, R. T., \& Leistico, A.-m. R. (2006). Psychopathy, empathy, and perspective taking ability in a community sample: implications for the successful psychopathy concept. International Journal of Forensic Mental Health, 5(2), 133-149. Retrieved from http://doi.org/10.1080/14999013.2006. 10471238

Pincus, A. L. \& Lukowitsky, M. R. (2010). Pathological narcissism and narcissistic personality disorder. Annual Review of Clinical Psychology, 6, 421-446. Retrieved from http://doi.org/10.1146/annurev.clinpsy.121208. 131215

Raskin, R. \& Terry, H. (1988). A principal-components analysis of the narcissistic personality inventory and further evidence of its construct validity. Journal of Personality and Social Psychology. Retrieved from. Retrieved from http://psycnet.apa.org/journals/psp/54/5/890/

Rosenberg, M. (1965). Society and the adolescent self-image. American Sociological Review (Vol. 31. Retrieved from http : / / doi . org / /S0034 98872009000600009

Rozenblatt, S. (2002). In defense of the self: the relationship of self-esteem and narcissism to aggressive behavior. Dissertation Abstracts International: Section B: The Sciences and Engineering, 63, 4.

Schmitt, D. P. \& Allik, J. (2005). Simultaneous administration of the rosenberg self-esteem scale in 53 nations: exploring the universal and culture-specific features of global self-esteem. Journal of Personality and Social Psychology, 89(4), 623-642. Retrieved from http: //doi.org/10.1037/0022-3514.89.4.623

Skeem, J. L., Poythress, N., Edens, J. F., Lilienfeld, S. O., \& Cale, E. M. (2003). Psychopathic personality or personalities? Exploring potential variants of psychopathy and their implications for risk assessment. Aggression and Violent Behavior, 8(5), 513-546. Retrieved from http://doi.org/10.1016/S1359-1789(02)00098-8

The Quantitative Methods for Psychology 
Widom, C. S. (1977). A methodology for studying noninstitutionalized psychopaths. Journal of Consulting and Clinical Psychology, 45(4), 674-683. Retrieved from http://doi.org/10.1037/0022-006X.45.4.674
Wink, P. (1991). Two faces of narcissism. Journal of Personality and Social Psychology, 61(4), 590-597. Retrieved from http://doi.org/10.1037/0022-3514.61.4.590

\section{Citation}

Durand, G. (2016). A replication of "using self-esteem to disaggregate psychopathy, narcissism, and aggression (2013)". The Quantitative Methods for Psychology, 12(2), r1-r5. doi:10.20982/tqmp.12.2.r001

Copyright (C 2016, Durand. This is an open-access article distributed under the terms of the Creative Commons Attribution License (CC BY). The use, distribution or reproduction in other forums is permitted, provided the original author(s) or licensor are credited and that the original publication in this journal is cited, in accordance with accepted academic practice. No use, distribution or reproduction is permitted which does not comply with these terms. 